\section{Hyperimmunoglobulin E syndrome presenting as osteogenesis imperfecta in a 3 year old child}

\author{
Stephen Gorgas, ${ }^{1}$ Walid Abuhammour, ${ }^{2}$ \\ R. Alexander Blackwood \\ 'Department of Pediatrics and \\ Communicable Diseases, University of \\ Michigan Medical School, Ann Arbor, MI; \\ 2Department of Pediatrics, Hurley \\ Medical Center, Flint, MI, USA
}

\section{Abstract}

We present a case of hyperimmunoglobulin E (hyper-IgE) syndrome in a three year old boy. There are many pitfalls in diagnosing this disease in the very young population, mainly due to the ambiguity of some diagnostic criteria in this population. Recognizing this syndrome early in life can potentially be very beneficial to the patients involved and the medical system as a whole. Early diagnosis can lead to fewer diagnostic tests, fewer referrals, and more focused exams, thus potentially reducing medical cost while also reducing the number of serious infections later in life, including those which are potentially fatal. Additionally, a wellknown association between lymphoma and hyper-IgE syndrome has been established; while no recommendations are currently in place for screening, early diagnosis could help medical providers have a higher threshold for diagnosis of this disease.

\section{Introduction}

The hyperimmunoglobulin E (hyper-IgE) syndromes were initially described as a single entity - Job Syndrome - in 1966 in two girls who presented with recurrent cold Staphylococcal abscesses, severe eczema, recurrent bronchopulmonary infections, and elevated serum IgE. ${ }^{1}$ Generally, the hyper-IgE syndromes were thought of as primary immunodeficiency diseases and could be grouped into three general categories: autosomal dominant (AD), autosomal recessive (AR), and sporadically occurring. Recurrent skin abscesses due to Staphylococcal and Candidal species heralded this disease. ${ }^{2}$ Autosomal dominant hyperimmunologlobulin E syndrome is characterized by a mutation in the STAT3 gene and is associated with the classical picture of immunodeficiency as well as non-immunological features including characteristic facial features, retained primary teeth, hyperextensibility, recurrent pathological fractures, and scoliosis. ${ }^{2-4}$ Autosomal recessive hyperimmunoglobulin $\mathrm{E}$ syndrome is a distinct disease entity characterized by more severe viral infections and neurological manifestations and without the skeletal or dental abnormalities seen in their autosomal dominant counterparts. ${ }^{5}$ In general, non-immunological manifestations of hyperimmunoglobulin $\mathrm{E}$ syndrome do not appear until well into childhood, but are almost always present after the age of $8 .^{2}$

\section{Case Report}

A three and a half year old boy was referred to Pediatric Infectious Disease clinic with a history of asthma, environmental allergies, multiple lung infections, long bone fractures, and hand-foot-mouth disease, for evaluation of recurrent skin abscesses and bullae. By the time of evaluation in Pediatric Infectious Disease Clinic a, referral to genetics had already been initiated to evaluate the child for Osteogenesis Imperfecta because of the history of recurrent long bone fractures.

According to the patient's mother, the abscesses and bullae usually occurred on the face and were generally of rapid onset. Most often, they began as a pimple on the cheek in the morning and progress forming large mildly erythematous bullae by the afternoon. Multiple lesions had been lanced and cultured, most often revealing Staphylococcal species. The mother first noticed very bad lesions on the patient's face as a small infant, initially attributing these lesions to bad baby acne; however, the complexion was much worse than her other children, as well as other children who she knew. Additionally, the patient also experienced multiple, severe blisters over the leg when a cast was removed due to a distal tibia fracture. Additionally, approximately one and a half months prior to evaluation the patient was admitted to an outside hospital for recurring bullae on the medial aspect of the left foot. These bullae were surgically debrided and the fluid expressed was cultured, revealing budding yeast. The patient had a similar infection when he was three years old. At that time a culture from the lesion revealed yeast and the patient improved with oral fluconazole.

The patient was the product of a 37 week 2 day uncomplicated pregnancy, but was hospitalized in the NICU for ten days, requiring mechanical ventilation secondary to pulmonary edema.

A review of the patients past medical history revealed a combination left tibia and fibula fractures at age 21 months, a combination left radius and ulna fracture at 29 months, and a fracture of the left tibia at 41 months. Each
Correspondence: R. Alexander Blackwood, Department of Pediatrics and Communicable Diseases, University of Michigan Medical School, D5101 Medical Professional Building/SPC 5718, 1500 East Medical Center Drive, Ann Arbor, MI 48109-5718, USA.

Tel. +1.734.7632440 - Fax: +1.734.2323859.

E-mail: rab@umich.edu

Key words: hyper-IgE syndrome, recurrent fractures, recurrent infections, rare diseases.

Conflict of interests: the authors report no conflict of interests.

Received for publication: 30 November 2012.

Revision received: 12 March 2013.

Accepted for publication: 19 March 2013.

This work is licensed under a Creative Commons Attribution NonCommercial 3.0 License (CC BYNC 3.0).

(C) Copyright S. Gorgas et al., 2013

Licensee PAGEPress, Italy

Infectious Disease Reports 2013; 5:e6

doi:10.4081/idr.2013.e6

instance was due to minor trauma.

Laboratory studies obtained from the outside hospitalization revealed a white blood cell count of $11.4 \mathrm{cell} / \mathrm{cm}^{3}$, hemoglobin of $12.0 \mathrm{~g} / \mathrm{dL}$, and platelets of $385,000 \mathrm{cel} / \mathrm{cm}^{3}$. The differential demonstrated $52 \%$ lymphocytes, $5 \%$ monocytes, $11 \%$ eosinophils, $31 \%$ neutrophils, and $1 \%$ basophils. The erythrocyte sedimentation rate (ESR) and C-reactive protein (CRP) were both normal. A biopsy of the debrided tissue on his left foot revealed dermal changes consistent with a hypersensitivity reaction to a fungal infection. Direct immunofluorescence shows weakly patchy granular dermal-epithelial junction of IgM and C3.

The lesions responded to intravenous ambisome followed by Itraconazole. The subtyping of IgG were within normal limits, IgG1 of 894 $\mathrm{mg} / \mathrm{dL}, \operatorname{IgG} 2$ of $164 \mathrm{mg} / \mathrm{dL}$, IgG3 of $17 \mathrm{mg} / \mathrm{dL}$, and IgG4 of $133 \mathrm{mg} / \mathrm{dL}$, with a normal antibody response to the Diptheria toxoid and Tetanus toxoid and T and B cell subtypes were normal.

Partial immunizations had been given to date and the patient history revealed allergies to sulfa drugs, eggs, and some wheat products by skin test. His family history was significant for a paternal grandmother with CVID and asthma, asthma and allergies on the paternal side, and the patient's mother and maternal grandmother had systemic lupus.

On physical exam, in Pediatric Infectious Disease Clinic at the University of Michigan, the height was in the $89^{\text {th }}$ percentile, the weight is in the $96^{\text {th }}$ percentile, and he appeared as a playful young boy in no apparent distress. There were multiple small, non-erythematous, hard papules over the cheeks and 
Table 1. National Institute of Health scoring system for hyperimmunoglobulin E syndrome.

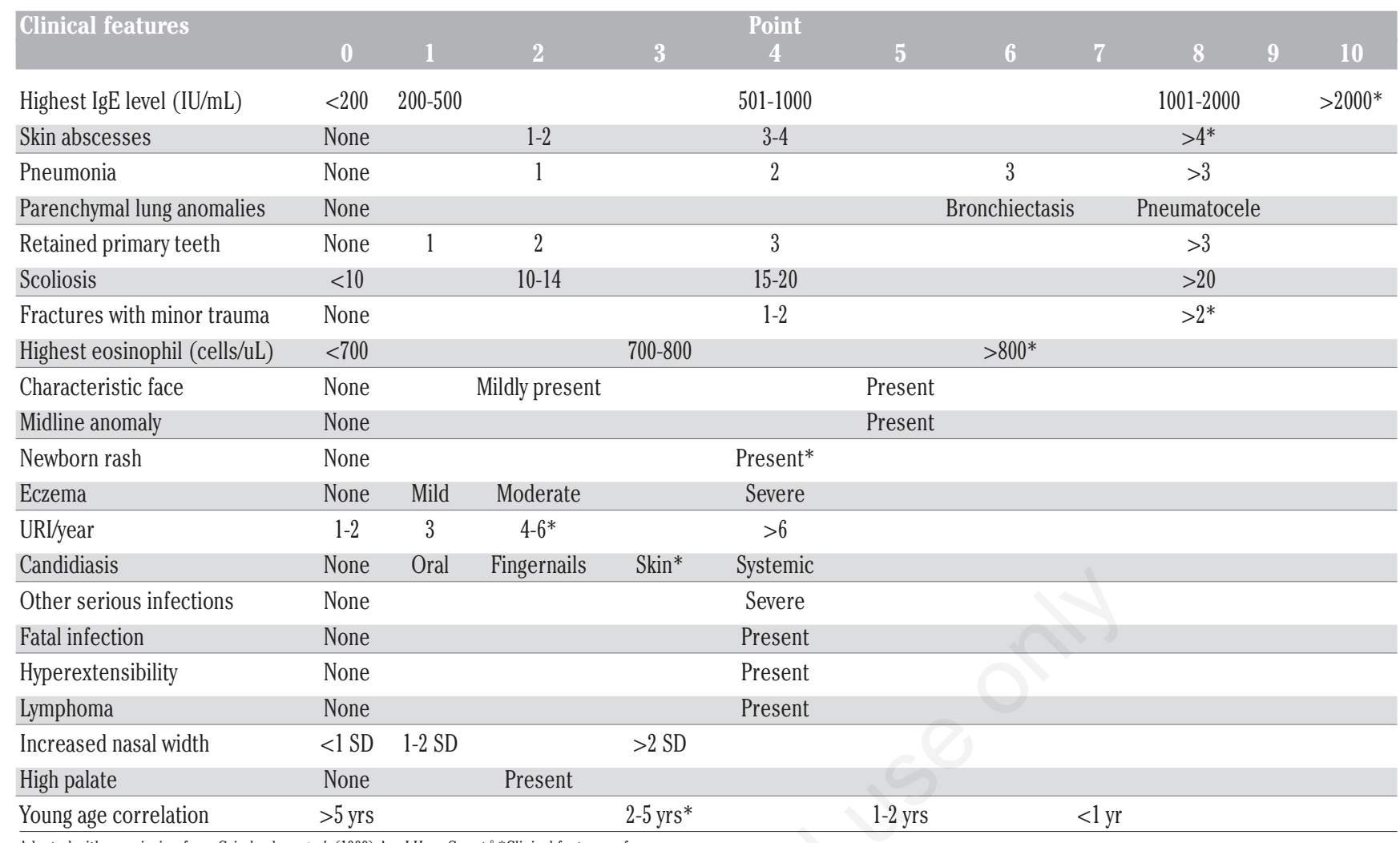

Adapted with permission from Grimbacher et al. (1999) Am J Hum Genet. ${ }^{*}$ Clinical features of case.

Table 2. Comparison of typical cohort of HIES patients and case.

\begin{tabular}{lc} 
Recurrent pneumonia & $85-87 \%$ \\
Eczema & $90-100 \%$ \\
\hline Recurrent skin abscesses* & $86-87 \%$ \\
Characteristic face** & $83 \%$ \\
\hline Failure to shed deciduous teeth** & $69 \%$ \\
Lung cyst formation & $63 \%$ \\
\hline Eosinophilia & $72-93 \%$ \\
Newborn rash* & $61-81 \%$ \\
\hline Other unusual infections & $50 \%$ \\
Increased interalar distance** & $45 \%$ \\
\hline Cathedral palate & $49 \%$ \\
Intraoral lesions & $93 \%$ \\
\hline Hyperextensibility & $43-68 \%$ \\
Pathologic bone fractures* & $34-71 \%$ \\
\hline Recurrent upper respiratory infections * & $45 \%$ \\
Candidiasis* & $41-83 \%$ \\
\hline Scoliosis & $24-63 \%$ \\
Midline anomaly & $14 \%$ \\
\hline
\end{tabular}

Adapted from Woellner et $a l^{3}$ and Sowerwine KJ et al. ${ }^{13}$ * Case features. ${ }^{* *}$ Age dependent features. bridge of his nose. The facies were not dimorphic and the dentition was good. No blue tint of hue was noted in the sclera and the pupils were equal round and reactive to light. There was no cervical lymphadenopathy with no other masses in the neck were appreciated. The lungs were clear to auscultation bilaterally. The abdomen was soft, non-tender, non-distended with no hepatosplenomegaly. The medial aspect of the left foot had new granulation tissue with a lesion approximately $3 \mathrm{~cm}$ by $4 \mathrm{~cm}$ from a previous bulla. New bullae formation was occurring on the periphery of the healing lesion. Muscle mass, strength and tone were within normal limits and the joints were not hyper-extensible. The neurologic exam was grossly intact.

Laboratory studies obtained from Pediatric Infectious Disease Clinic revealed an immunoglobulin panel with an IgA level of 214 $\mathrm{mg} / \mathrm{dL}$ (normal $15-160 \mathrm{mg} / \mathrm{dL}$ ), IgG level of 1260 $\mathrm{mg} / \mathrm{dL}$ (normal 405-1160 mg/dL), IgM level of $117 \mathrm{mg} / \mathrm{dL}$ (normal 40-190 mg/dL), and an IgE level of $>10,000 \mathrm{kU} / \mathrm{L}$ (normal $0-150 \mathrm{kU} / \mathrm{L}$ ). The subtyping of IgG were within normal limits, IgG1 of $947 \mathrm{mg} / \mathrm{dL}$, IgG2 of $92 \mathrm{mg} / \mathrm{dL}$, IgG3 of $18.3 \mathrm{mg} / \mathrm{dL}$, and IgG4 of $42 \mathrm{mg} / \mathrm{dL}$, with a normal antibody response to the Rubella. A CH50 level was normal at 101 units (normal 52-128 units). The ESR and CRP were normal and a Gram stain and culture from the left foot were negative.

\section{Discussion}

This patient was referred to the Pediatric Infectious Diseases and Immunology Service at the University of Michigan, with suspected Osteogenesis imperfecta (OI), for evaluation of the immune system due to a history of frequent infections. OI is a rare genetic disorder (85-90\% autosomal dominant) caused by a mutation in one of the type I collagen genes. ${ }^{6,7}$ Type I Collagen is an important component of the bone matrix and collagen homeostasis is important for both bone and connective tissue integrity. Patients with $\mathrm{OI}$ are characterized by bone fragility resulting in frequent fractures. There are VIII types of OI which progress in severity and clinical manifestations. Clinical findings in conjunction with the multiple fractures include loose joints and muscle weakness blue sclera, triangular face, brittle teeth, hearing loss, short stature, barrel-shaped rib cage, respiratory problems, underdeveloped lungs, spinal curvature, coxa vera, and extremely poor skeletal mineralization, none of which were present in this patient. De novo mutations in COL1A1 or COL1A2 account for a majority of the cases of $\mathrm{OI}$ which can be confirmed by molecular genetic testing or collagen biopsy analysis.

While frequent fractures and a variety of collagen related problems are characteristic of $\mathrm{OI}$, 
recurrent infections and susceptibility to Staphylococcus aureus and candida species are not. However, infections with both organisms as well as frequent fractures can be found in patients with hyperimmunoglobulin E syndrome. Attempts have been made to establish diagnostic criteria for hyper-IgE, many of which utilize non-immunologic factors as guides. ${ }^{3,8-11}$ An NIH scoring system consists of 20 different characteristics and assigning a varying number of points to each fulfilled criteria has been proposed. ${ }^{8}$ Using this system, scores of greater than 40 out of a theoretical maximum of 109 made the diagnosis more likely and scores less than 20 made the diagnosis less likely. ${ }^{3}$ Relying on non-immunologic factors to aid in diagnosing hyperimmunoglobulin E syndrome presents a unique challenge to early detection in childhood, because many skeletal features such as scoliosis and characteristic facial features occur with disease progression rather than with initial symptoms. ${ }^{2}$ There have been many reports of this disorder being undiagnosed or misdiagnosed as osteogenesis imperfecta, Ehlers-Danlos syndrome, medication non-compliance, and non-accidental trauma, particularly in the young patient. ${ }^{2}$ The NIH scoring system that has been utilized in many studies has an age correction factor to address this very issue, early diagnosis is difficult. The patient, presented in the case report, would have a score of 37 on presentation to the Pediatric Infectious Diseases Clinic (Table 1). Because of the unusual cutaneous manifestations of yeast serum IgE levels were obtained [>10,000 kU/L (normal 0-150 kU/L)] increasing the NIH score to 47 increasing the likelihood of a diagnosis of hyper-IgE syndrome. Genetic testing was performed by confirming a mutation in STAT 3 and a diagnosis of autosomal dominant hyper-IgE syndrome. Autosomal recessive hyper-IgE syndrome is caused by mutations in DOCK8. These patients have less skeletal and dental involvement but are more susceptible to viral infections such as severe Molluscum contagiosum..$^{13}$ In a recent review of 100 patients, an attempt to characterize the frequency of the characteristics was made. ${ }^{3}$ The most frequent manifestations, characteristic face $(82.8 \%)$, failure to shed deciduous teeth (69\%), and lung cyst formation (68\%) were not present in our patient, likely because he was too young to do so. However, frequent pathologic fractures was present in our patient, but was seen in only $34 \%$ of the cohort studied (Table 2). The NIH scoring system still represents a means of prioritizing the diagnostic evaluation of a patient with frequent fractures.

\section{References}

1. Davis SD, Schaller J, Wedgwood RJ. Job's syndrome. Recurrent, cold, staphylococcal abscesses. Lancet 1966;1:1013-5.

2. Grimbacher B, Holland SM, Gallin JI, et al. Hyper-IgE syndrome with recurrent infections--an autosomal dominant multisystem disorder. N Engl J Med 1999;340:692702.

3. Woellner C, Gertz EM, Schäffer AA, et al. Mutations in STAT3 and diagnostic guidelines for hyper-IgE syndrome. J Allergy Clin Immunol 2010;125:424-32.

4. Holland SM, DeLeo FR, Elloumi HZ, et al. STAT3 mutations in the hyper-IgE syn- drome. N Engl J Med 2007;357:1608-19.

5. Renner ED, Puck JM, Holland SM, et al. Autosomal recessive hyperimmunoglobulin E syndrome: a distinct disease entity. J Pediatr 2004;144:93-9.

6. Steiner RD, Adsit J, Basel D. COL1A1/2related osteogenesis imperfecta. In: Pagon RA, Bird TD, Dolan CR, et al., eds. GeneReviews $^{\mathrm{TM}} \quad$ [Internet]. Seattle: University of Washington; 1993. Available from: http://www.ncbi.nlm.nih.gov/books/ NBK1295/.

7. Cundy T. Recent advances in osteogenesis imperfecta. Calcif Tissue Int 2012;90:43949.

8. Walsh J, Reardon W. Job syndrome masquerading as non-accidental injury. Arch Dis Child 2008;93:65-7.

9. Schimke LF, Sawalle-Belohradsky J, Roesler J, et al. Diagnostic approach to the hyper-IgE syndromes: immunologic and clinical key findings to differentiate hyperIgE syndromes from atopic dermatitis. J Allergy Clin Immunol 2010;126:611-7.

10. Grimbacher B, Schäffer AA, Holland SM, et al. Genetic linkage of hyper-IgE syndrome to chromosome 4. Am J Hum Genet 1999;65: 735-44.

11. Freeman AF, Holland SM. Clinical manifestations of hyper IgE syndromes. Dis Markers 2010;29:123-30.

12. Freeman AF, Holland SM. Clinical manifestations, etiology, and pathogenesis of the hyper-IgE syndromes. Pediatr Res 2009;65: 32R-37R.

13. Sowerwine KJ, Holland SM, Freeman AF. Hyper-IgE syndrome update. Ann NY Acad Sci 2012;250:25-32. 